ORIGINAL ARTICLE

\title{
Changes in joint position sense after surgically treated chronic lateral ankle instability
}

\author{
T Halasi, Á Kynsburg, A Tállay, I Berkes
}

Br J Sports Med 2005;39:818-824. doi: 10.1136/bjsm.2004.016527

See end of article for authors' affiliations

Correspondence to:

Dr Halasi, Department of

Sports Surgery, National Institute for Sports

Medicine, Budapest 1123,

Hungary; kynsburg@

medscape.com

Accepted 30 March 2005
Background: A search of the literature shows that the effect of surgery on ankle proprioception has been hardly investigated.

Objective: To examine the effect of anatomical reconstruction of the anterolateral capsuloligamentous complex on ankle joint position sense.

Methods: A prospective study using the "slope box" test. Ten consecutive patients were included in the study, and 10 healthy athletes represented the control group.

Results: Similar test-retest reliability rates (overall reliability $0.92 ; p=0.0013$ ) were obtained to those of the original designers of the method. There were no significant differences with respect to side dominance $(p=0.9216)$. Investigation of the characteristics of mean absolute estimate errors showed that the controls tested became error prone in the range of slope altitudes $7.5-25^{\circ}$ in every direction, compared with the range $0-5^{\circ}$ (range of $p$ values $0.00003-0.00072$ ). The results of the intervention group showed that, for the two main directions of interest (anterior and lateral), preoperative differences in mean absolute estimate errors between injured (anterior 3.91 (2.81) ; lateral 4.06 (2.85) $)$ and healthy (anterior 2.94 (2.21) $)^{\circ}$ lateral $3.19(2.64)$ ) sides (anterior, $p=0.0124$; lateral, $p=0.0250$ ) had disappeared (postoperative differences: anterior, $p=0.6906$; lateral, $p=0.4491$ ). The afflicted ankle had improved significantly after surgery in both important directions (anterior, $p<0.0001$; lateral, $p=0.0023$ ).

Conclusions: The study shows that differences in joint position sense between healthy and injured ankles disappeared as the result of surgery. Preoperative data show that proprioceptive malfunction is a cause of functional instability. If treatment is by means of surgery, the retensioning of the original anterolateral structures is inevitable, even if other grafting or surgical techniques are used.
A nkle sprain is the most common sports injury, predominantly $(85-90 \%)$ affecting the lateral ligaments of the ankle. The resulting chronic talocrural instability adversely affects sports performance and often everyday living as well. ${ }^{1-4}$ The main causes of the functional instability are mechanical instability, peroneal muscle weakness, and proprioceptive deficit. ${ }^{13-6}$ It is generally accepted that surgical treatment is only necessary in $10-30 \%$ of cases, after unsuccessful conservative treatment. ${ }^{2-4}$ 7-9

An increasingly popular stabilising surgical procedure is the anatomical reconstruction or delayed repair. ${ }^{2-4}$ 8-13 $^{-1}$ Its advantages are: reproduction of the original anatomical conditions while leaving other structures, especially tendons, unaffected; small incision and little tissue damage; fewer complications; effective stabilisation with less impairment of range of motion compared with other methods. ${ }^{2-4} 8-13$

The modified Broström procedure, ${ }^{14}$ described by Karlsson et $a l^{2}$ in 1988, involves the shortening, reinsertion, and duplication of the anterolateral ligaments and capsule. There is no clinical evidence, only logical supposition, that this technique must have an effect on the proprioceptive function of the ankle. ${ }^{31012}$ We hypothesised that anatomical reconstruction should improve decreased receptor activity by retensioning slackened lateral structures of the talocrural joint. $^{3}$

There are numerous accepted methods for the assessment of ankle joint position sense. ${ }^{15}$ We used the "slope box" test, first applied and described by Robbins et $a l,{ }^{16}$ as its use is very feasible for a clinical study.

The aim of our prospective study was to document the effects of anatomical reconstruction of the anterolateral capsuloligamentous complex on ankle joint position sense.

\section{METHODS}

The slope box test ${ }^{16}$ was used to assess joint position sense. Eleven wooden platforms with a basal area of $30 \times 30 \mathrm{~cm}$ were constructed, and covered with slip proof rubber material. The platforms were inclined at angles varying by $2.5^{\circ}$ between $0^{\circ}$ and $25^{\circ}$. With the four directional rotation of

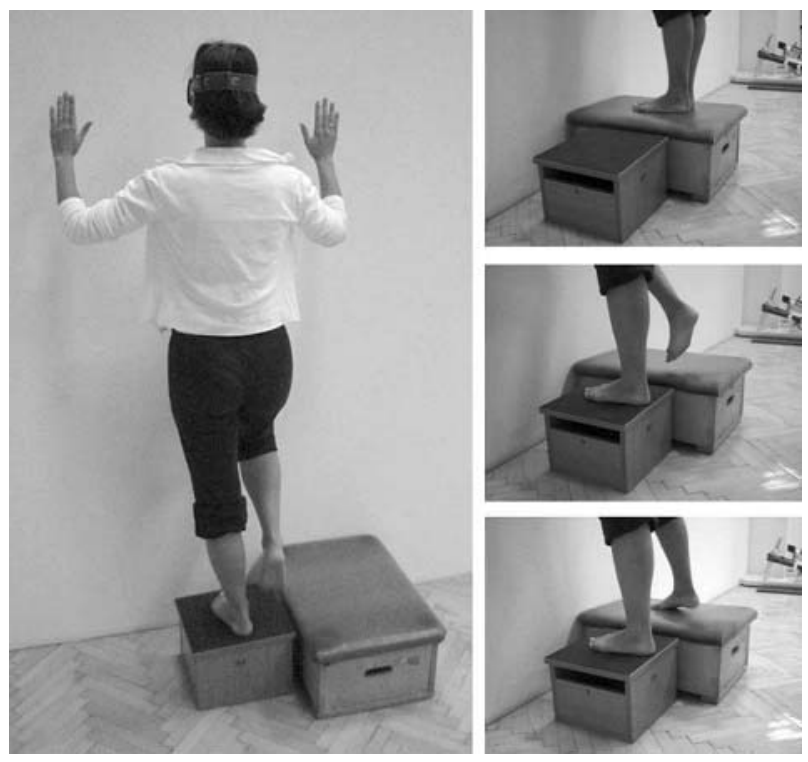

Figure 1 Joint position sense testing with the slope-box test. The subject has given permission for publication of this figure. 


\begin{tabular}{|c|c|c|c|}
\hline & $\begin{array}{c}\text { Control } \\
(n=10)\end{array}$ & $\begin{array}{l}\text { Operative } \\
(n=10)\end{array}$ & $\mathrm{p}$ Value \\
\hline \multirow[t]{2}{*}{ Age (years) } & $23.0(5.8)$ & $25.5(7.3)$ & $>0.05$ \\
\hline & $(16.2-31.6)$ & $(16.0-37.6)$ & \\
\hline \multirow[t]{2}{*}{ Follow up (weeks) } & - & $7.4(1.0)$ & - \\
\hline & & $(6.0-9.1)$ & \\
\hline \multirow[t]{2}{*}{ Height $(\mathrm{cm})$} & $172.8(8.1)$ & $172.5(4.9)$ & $>0.05$ \\
\hline & (163-185) & $(167-180)$ & \\
\hline \multirow[t]{2}{*}{ Weight $(\mathrm{kg})$} & $66.5(11.3)$ & $66.0(7.5)$ & $>0.05$ \\
\hline & (56-85) & (56-78) & \\
\hline \multirow[t]{2}{*}{ BMI $\left(\mathrm{kg} / \mathrm{m}^{2}\right)$} & $22.1(1.8)$ & $22.1(1.5)$ & $>0.05$ \\
\hline & (20.2-25.4) & $(20.1-24.1)$ & \\
\hline Male/female & $5 / 5$ & $5 / 5$ & $>0.05$ \\
\hline \multicolumn{4}{|l|}{ Affected side } \\
\hline Left/right & - & $2 / 8$ & - \\
\hline Dominant/non-dominant & - & $7 / 3$ & - \\
\hline \multicolumn{4}{|l|}{ Sports activity } \\
\hline Top level & 6 & 1 & \\
\hline Competitive & 4 & 5 & $>0.05$ \\
\hline Recreational & 0 & 4 & \\
\hline
\end{tabular}

the platforms, there were $4 \times 11$ testing positions available altogether (fig 1).

Patients were asked to step on to the platforms with one foot, placing their entire weight on that supporting foot. During testing, patients were given glasses darkened on the bottom so that they could not see downwards. To exclude the effects of footwear, all testing was conducted with the subject barefoot (fig 1).

Before testing, patients were informed that their task was to estimate the degree of incline on to which they had stepped, to determine the direction (whether it was outward, inward, forward, or backward-that is, lateral, medial, anterior, or posterior), and to estimate the steepness of the incline on a scale from 0 to $15\left(0^{\circ}\right.$ to $\left.37.5^{\circ}\right)$, enabling an overestimation of up to $12.5^{\circ}$.

Patients were always tested for all 44 positions in four series of 11. At the beginning, each patient was shown the platforms inclined at $0^{\circ}, 12.5^{\circ}$, and $25^{\circ}$ (inclines 0,5 , and 10 as scaled for patients) for reference. When designing the study, we randomly determined the order in which subjects were presented with the 44 types of incline. This order was then followed exactly for every patient. To eliminate a learning effect, subjects did not see the platforms, did not know the grade of inclination (except for reference), and did not receive any feedback on the accuracy of their guesses. As

\begin{tabular}{ll}
$\begin{array}{l}\text { Table } 2 \\
\text { test }\end{array}$ & Test-retest reliability of the slope box \\
\hline & Splithalf reliability \\
\hline Medial & 0.90 \\
Posterior & 0.91 \\
Lateral & 0.93 \\
Anterior & 0.91 \\
Overall & $0.92(p=0.0013)$ \\
\hline
\end{tabular}

each subject was tested for both legs, there were $2 \times 44$ measurements available for each one.

Twenty people participated in the study. Ten patients, belonging to the operative group, were admitted to the Department of Sports Surgery and assigned to the study in random order of arrival. Criteria for inclusion were: elective Karlsson procedure for chronic ankle instability (functional and mechanical); unsuccessful conservative treatment; aged 16-40 years; active in sport; unaffected contralateral ankle. Exclusion criteria were: previous fracture or muscle injury of the lower extremities; previous ankle surgery; known neurological or otological disease; restricted talocrural function; intra-articular lesions of the talocrural joint.

During the study period (March to December 2002), of the 17 patients encountered, 14 met the inclusion criteria, but after exclusions 10 actually remained in the study. The fact that there were equal numbers of men and women (five of each) was due to chance. The first measurements were performed on the day before surgery. The same operative method, described by Karlsson et al, ${ }^{2}$ was used for all patients. After surgery, patients wore a cast for four weeks. After cast removal, physiotherapy involved only range of motion exercises; no proprioceptive training was provided. We conducted a follow up assessment 6-9 weeks after surgery, when the ankle that had been operated on had regained similar range of motion to the healthy ankle.

The control group contained 10 healthy athletes who were visiting the institute for regular check ups. Criteria for selection and inclusion were: competitive athlete; aged 16-40 years; negative medical history and physical status; equal numbers of men and women.

Exclusion criteria were the same as for the operative group. Healthy controls only took part in one examination, except for the first three who were examined on two consecutive days to test the reliability of the method.

The baseline data of the two groups did not differ significantly (table 1). The dominant side was determined using a ball kicking test. 
Table 3 Results of the control group

\begin{tabular}{llll}
\hline & \multicolumn{2}{l}{ Mean absolute estimate errors } & \\
\cline { 2 - 3 } 0 & $\begin{array}{l}\text { Dominant } \\
(\mathbf{n}=10)\end{array}$ & $\begin{array}{c}\text { Non-dominant } \\
(\mathbf{n}=10)\end{array}$ & $\mathbf{p}$ Value \\
\hline Direction & & & \\
Medial & $2.74^{\circ}(2.56)^{\circ}$ & $2.71^{\circ}(2.60)^{\circ}$ & 0.9216 \\
Posterior & $2.88^{\circ}(2.59)^{\circ}$ & $3.01^{\circ}(2.98)^{\circ}$ & 0.7125 \\
Lateral & $2.88^{\circ}(2.76)^{\circ}$ & $2.41^{\circ}(2.29)^{\circ}$ & 0.0988 \\
Anterior & $2.42^{\circ}(2.61)^{\circ}$ & $2.30^{\circ}(2.19)^{\circ}$ & 0.6775 \\
All four directions & $2.92^{\circ}(2.62)^{\circ}$ & $2.79^{\circ}(2.53)^{\circ}$ & 0.4468 \\
Two directions (lateral + anterior) & $2.77^{\circ}(2.69)^{\circ}$ & $2.47^{\circ}(2.23)^{\circ}$ & 0.1502 \\
\hline Values are mean (SD). & & & \\
\hline
\end{tabular}

The absolute estimate error, applied to characterise the accuracy of estimating inclinations, is the absolute value of the difference in degrees between the estimated and actual inclination of the platform. The mean absolute estimate error, which enables comparisons within and between groups, also allows comparisons with the results of other researchers on position sense testing.

Subject data were recorded on MS Excel sheets, and data were analysed using Statistica 6.0. The reliability of the method was determined by analysing relative errors in estimation between the first and second tests by the first three control subjects. Relative error is the difference between estimated and actual slope amplitude (inclination) with a positive or negative sign. Final assessment involved repeated reliability analysis, and statistical significance was determined by one way analysis of variance. Otherwise, the comparison of any two groups was based on the absolute errors. For comparison of the estimates made for the same group at two different times, we used a single sample, paired $t$ test with two sided significance. For comparison of the results of two separate groups, we used a two sample, two sided $t$ test. Statistical significance was assumed at $\mathrm{p}=0.05$.

\section{RESULTS}

The overall reliability of the method was 0.92 (table 2).

The direction of inclination was misjudged 17 times out of 2904 estimates $(0.6 \%)$. These results were therefore unsuitable for further analysis. The estimate errors (in degrees) in these cases were, however, included in the overall results.

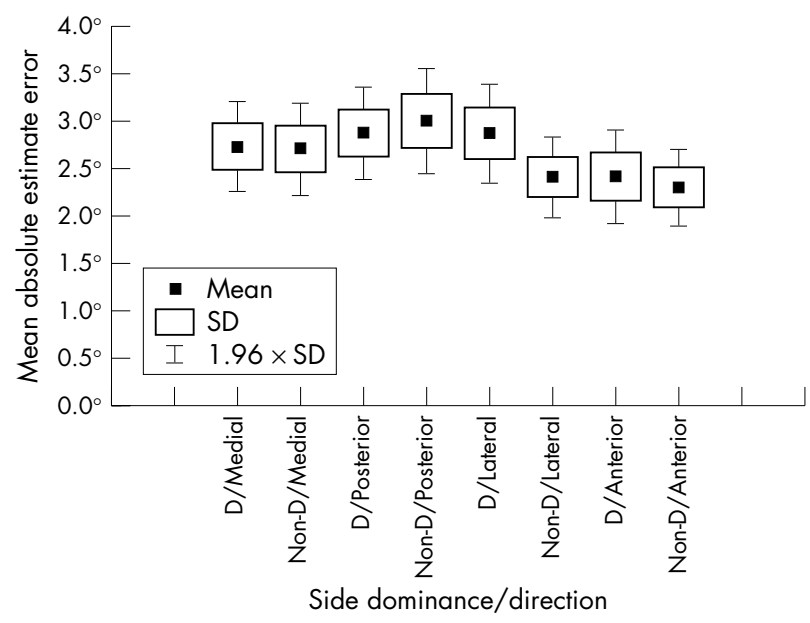

Figure 2 Differences in joint position sense function of dominant and non-dominant ankles in the control group. Box and whisker diagram of mean absolute estimate errors with regard to different directions. D, Dominant side; Non-D, non-dominant side.
In the control group, we examined the average value of the absolute estimate error with respect to side dominance in relation to inclination in all four directions (combined and separately) and found no significant differences (table 3). There was also no difference between the performance of the men and women. The mean (SD) absolute estimate error was $2.86(1.89)^{\circ}$ in the male subjects and $2.85(2.09)^{\circ}$ in the female subjects $(p=0.9321)$. As there were no significant differences in relation to side dominance or sex, we used the results of all 20 healthy ankles in the control group as a baseline for later comparisons (fig 2).

Figure 3 shows separately in four directions the changes in mean absolute estimate errors in relation to slope amplitudes. Curves running close to each other show no significant differences between dominant and non-dominant ankles. The steepness of all four curve pairs differs vastly below and above $7.5^{\circ}$ of inclination. This striking feature in the graphical representation prompted us to examine statistically possible differences between mean absolute estimate errors made in the $0-5^{\circ}$ range and the $7.5-25^{\circ}$ range. The difference proved to be strongly significant in all directions (table 4 ). As the mean estimate errors in the control group were larger in the $7.5-25^{\circ}$ range, when we were examining the operative group we performed separate statistical analyses in this range.

Table 5 summarises the results of the operative group throughout the whole range of inclinations. The mean absolute estimate error of the ankle that underwent surgery was significantly larger than that of the healthy ankle. After surgery, the ankle that was operated on improved significantly, while the results of the healthy ankle remained practically unchanged.

When considering the main effect of the surgical procedure-that is, re-establishment of the physiological supportive role of anterolateral structures-two directions ("forward" and "outward") deserve special attention. The net result of estimate errors in these directions provides more valuable information than overall values. Before surgery, the afflicted ankle showed a significantly higher mean absolute estimate error than the opposite ankle, whereas afterwards there was almost no difference between the two sides (table 5). No similar results were observed in the other two directions

Figure 4 shows the characteristics of the mean absolute estimate errors in the two important directions on the afflicted ankle. The continuous bold curves represent the preoperative function; mean absolute estimate errors are the highest in these. Dashed bold lines represent the postoperative results; improvement is demonstrated by these curves running well below the continuous bold ones. In the lateral direction, postoperative function proved to be even better in the higher inclinations than that of the control group (displayed by thin continuous lines).

The steepness of all curves on both charts changes similarly at $7.5^{\circ}$ of inclination. Because of facts highlighted above, the 

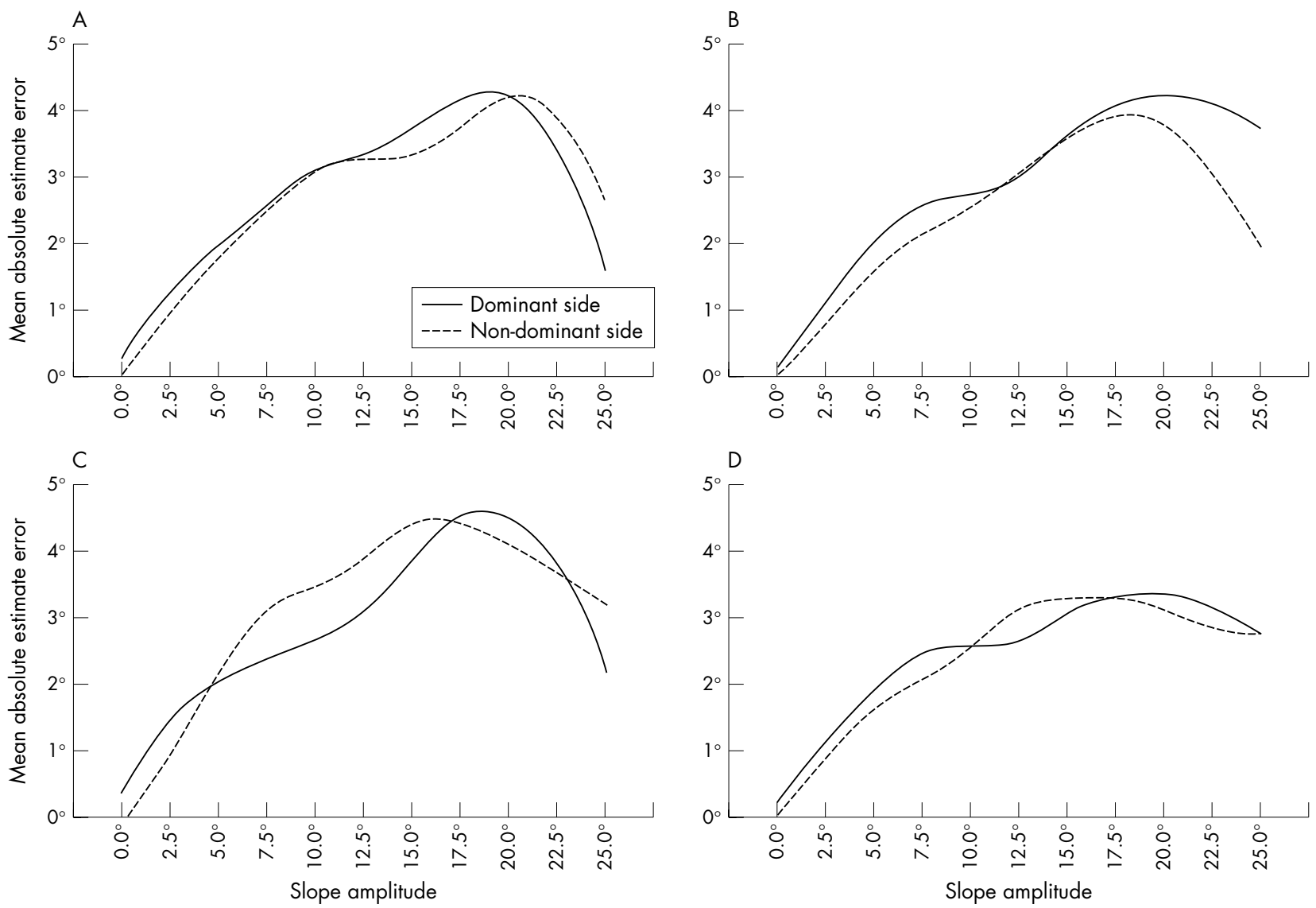

Figure 3 Characteristics of joint position sense function of dominant and non-dominant ankles in the (A) medial, (B) lateral, (C) posterior, and (D) anterior direction.

intervals between $7.5^{\circ}$ and $25^{\circ}$ allow a more exact comparison excluding the washout effect of the lower ranges of inclination.

Table 6 shows that, in the narrower and more specific interval, the mean absolute estimate error of the operated ankle was significantly (almost a whole degree) larger than that of the healthy ankle in both important directions. The improvement in mean absolute estimate error after surgery was also almost a whole degree in both "forward" and "outward" directions, meaning that the process of normalisation is characteristic of both directions and the improvement is statistically significant.

\section{DISCUSSION}

It is mainly accepted today that correct proprioceptive sensomotor function of the ankle joint is a key factor in both prevention and treatment of ligament injury and chronic instability. ${ }^{3} 461517$

Ashton-Miller ${ }^{18}$ defines strict guidelines for all research of this particular problem. He favours tests with weight bearing, reproducing the actual mechanism, such as the one developed by Robbins et $a l^{16}$ and used by us.

Gait, running, and landing movements are of utmost importance with regard to primary and recurrent injuries. ${ }^{18-20}$ However, modelling of landing can only be approximately reproduced because of the risk of injury.

Our method enables good modelling of the actual event as the subject transfers full body weight on to the examined leg. The direction and amplitude of the slope applied cannot be seen or anticipated by the subject. This model is of course also a compromise: the surface is even, there is no forward motion, and the speed is less than is characteristic of most sports. ${ }^{15} 20$ This method has been used previously for the examination of joint position sense..$^{15}{ }^{21}$ In our experience, its advantage is the simple technical requirements, but it is very time consuming. A fresh injury or reinjury and the absence of normal communicative skills on the part of the subject limit the applicability.

Robbins $e a^{16}$ found a test-retest reliability of 0.91 . This is similar to our data (0.92; table 2$)$. We found no significant

Table 4 Comparison of mean absolute estimate errors between two ranges of inclination in the control group

\begin{tabular}{|c|c|c|c|c|c|}
\hline & $\begin{array}{l}\text { Mean } \\
\left(0^{\circ}-5^{\circ}\right)\end{array}$ & $\begin{array}{l}\text { Mean } \\
\left(7.5^{\circ}-25^{\circ}\right)\end{array}$ & $t$ Value & df & $p$ Value \\
\hline Medial & 1.5625 & 3.3437 & -3.7761 & 98 & 0.00027 \\
\hline Posterior & 1.6250 & 3.6250 & -4.4207 & 98 & 0.00003 \\
\hline Lateral & 1.3125 & 3.2969 & -4.2828 & 98 & 0.00004 \\
\hline Anterior & 1.3750 & 2.8906 & -3.4925 & 98 & 0.00072 \\
\hline
\end{tabular}


Table 5 Results of the operative group in full range of inclination

\begin{tabular}{|c|c|c|c|}
\hline \multirow[b]{2}{*}{$0-25^{\circ}$} & \multicolumn{2}{|c|}{ Mean absolute estimate errors } & \multirow[b]{2}{*}{ p Value } \\
\hline & Before & After & \\
\hline \multicolumn{4}{|l|}{ All four directions } \\
\hline Operated & $3.48^{\circ}(2.83)^{\circ}$ & $2.86^{\circ}(2.34)^{\circ}$ & $<0.0001$ \\
\hline Non-operated & $3.00^{\circ}(2.63)^{\circ}$ & $3.02^{\circ}(2.49)^{\circ}$ & 0.8776 \\
\hline p Value & 0.0026 & 0.2685 & \\
\hline \multicolumn{4}{|c|}{ Two directions (lateral+anterior) } \\
\hline Operated & $3.40^{\circ}(2.78)^{\circ}$ & $2.72^{\circ}(2.37)^{\circ}$ & 0.0023 \\
\hline Non-operated & $2.75^{\circ}(2.31)^{\circ}$ & $2.71^{\circ}(2.24)^{\circ}$ & 0.8464 \\
\hline $\mathrm{p}$ Value & 0.0031 & 0.9646 & \\
\hline
\end{tabular}

difference between mean absolute estimate errors of dominant and non-dominant sides $\left(2.92^{\circ} \vee 2.79^{\circ}\right)$ and of men and women $\left(2.86^{\circ} \vee 2.85^{\circ}\right)$. This conforms with the findings of other authors on joint position sense testing. ${ }^{15} 1822$

There is some disagreement in the literature, however, about the role of proprioceptive malfunction. Glencross and Thornton $^{5}$ showed significant differences between injured and non-injured ankles with active position replication tests. Their results may lead to the conclusion that residual symptoms are consequences of receptor damage and malfunction of the sensorimotor system.

In conflict with this, Gross ${ }^{23}$ reported results on active and passive position reproduction, where recurrent ankle injuries did not feature. In the author's opinion, the reason for this may be a difference that is already present between the two groups (healthy and injured) before the measurements. Thus the proprioceptive malfunction may well be not a consequence of, but a reason for, ankle ligament injuries.

Our results agree at many points with those of Glencross and Thornton. ${ }^{5}$ Mean absolute estimate errors were higher in the range of steeper slope amplitudes, and the disturbance in joint position sense of the injured side was similarly proved.
There is also much controversy about the legacy of the proprioceptive theory when reviewing studies that used local anaesthesia of the ankle region or ligaments.

Feuerbach et $\mathrm{l}^{24}$ and Hertel et al ${ }^{25}$ performed a similar series of examinations with ligamentous anaesthesia on healthy ankles. The mean error of joint position sense was not affected adversely by anaesthesia. Konradsen et al ${ }^{20}$ made complex proprioceptive measurements before and after applying regional local anaesthesia to healthy ankles. They found that passive joint position sense decreased, whereas active position replication was not altered by anaesthesia. They concluded that the negative changes in passive joint position sense confirm the importance of the receptors in the ligaments and joint capsule with regard to this sensory function. However, the unaltered active joint position replication function underlined the compensating potentials of muscle and tendon receptors. In our study we only examined and confirmed the role of the sensory side of the proprioceptive system.

Konradsen and Magnusson ${ }^{22}$ published a simple and accurate method for testing active replication of joint position. The study group consisted of 23 recreational
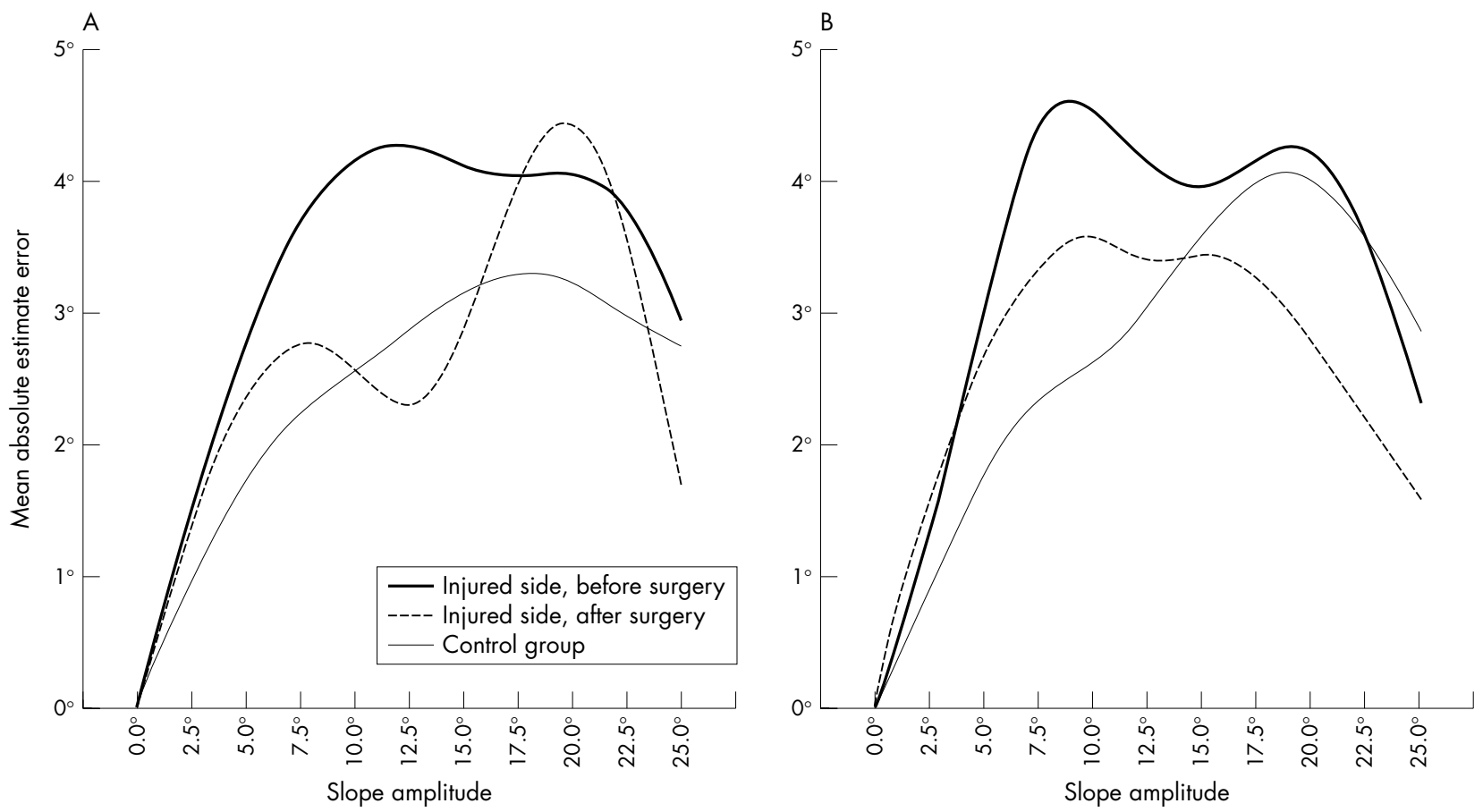

Figure 4 Preoperative and postoperative joint position sense characteristics of patients treated surgically for lateral ankle instability in the two main directions of interest: anterior (A); lateral (B). A comparison with the results of the control group. 


\begin{tabular}{|c|c|c|c|}
\hline \multirow[b]{2}{*}{$7.5-25^{\circ}$} & \multicolumn{2}{|c|}{ Mean absolute estimate errors } & \multirow[b]{2}{*}{ p Value } \\
\hline & Before & After & \\
\hline \multicolumn{4}{|l|}{ Anterior } \\
\hline Operated & $3.91^{\circ}(2.81)^{\circ}$ & $3.13^{\circ}(2.47)^{\circ}$ & 0.0425 \\
\hline Non-operated & $2.94^{\circ}(2.21)^{\circ}$ & $2.97^{\circ}(2.46)^{\circ}$ & 0.9335 \\
\hline $\mathrm{p}$ Value & 0.0124 & 0.6906 & \\
\hline \multicolumn{4}{|l|}{ Lateral } \\
\hline Operated & $4.06^{\circ}(2.85)^{\circ}$ & $2.94^{\circ}(2.57)^{\circ}$ & 0.0075 \\
\hline Non-operated & $3.19^{\circ}(2.64)^{\circ}$ & $3.19^{\circ}(2.21)^{\circ}$ & 0.9999 \\
\hline$p$ Value & 0.0250 & 0.4491 & \\
\hline
\end{tabular}

athletes, who were considered for surgery for chronic lateral talocrural instability. Significant preoperative differences (affected ankle versus controls; affected versus healthy ankle) established the proprioceptive malfunction of the injured side. This difference between unaffected and injured ankles was also significant in our group before surgery.

The work of Robbins et $a l^{16}$ provides the best basis for comparing basic data, as the technical details of our methods are identical. The only major difference was that the 24 healthy students in the study of Robbins et al wore their own sports shoes whereas in our study measurements were carried out with the subjects barefoot. The mean absolute estimate error was $3.95^{\circ}$ before and $4.81^{\circ}$ after sporting activity. The reason for the result being worse by about $1^{\circ}$ compared with our controls cannot be readily identified, but in their previous studies, in which testing was carried out with the subjects barefoot, they report a much better mean absolute estimate error of $1.96^{\circ}$.

Robbins et al chose the range of slope amplitudes of $10^{\circ}$ and above (where mean absolute estimate errors were higher) as the range of increased injury proneness, and used these data for further analysis. In our statistical analysis, however, we used $7.5^{\circ}$, which is a more accurate threshold, as differences between two sets of slope amplitudes are the most significant at this point.

The aim of our study was to provide evidence for the effectiveness of surgery on ankle joint position sense. No similar studies are available in the literature. A change in proprioceptive function through the retensioning of the anterolateral structures can only be expected after anatomical reconstructions (also known as delayed repairs). One particular method of this kind is the Karlsson procedure, which was also performed in the investigated cases. Curiously, the author of the technique did not mention in any of his numerous publications the possible positive proprioceptive effect of this type of surgery. ${ }^{2}{ }^{7826}$

Ahlgren and Larsson, ${ }^{10}$ Liu and Jacobson, ${ }^{12}$ Williams, ${ }^{9}$ and Mann et al $^{3}$ suggested that the beneficial proprioceptive effect of surgery may be the reason for the excellent functional results. These conclusions, stated by independent surgeons using similar surgical methods, were based mainly on already verified anatomical evidence. Lephart et $a l^{17}$ also stated that

\section{What is already known on this topic}

- Ankle sprain is the most common sports injury, affecting sports performance and everyday living

- Surgery is only necessary if conservative treatment is unsuccessful, but the effect of surgery on ankle proprioception has been hardly investigated there was enough physiological and anatomical evidence to support this theory.

Takebayashi et $a^{27}$ reported the presence of tension sensitive receptors in the lateral ankle ligaments, and mapped them exactly. According to these authors, the presence of the mechanoreceptors supports the theory that, after ligamentous injury, there is a disturbance in the proprioceptive afferentation, which causes a lack of effector-answer on sudden inversion. They also concluded that, of the surgical procedures available, those that preserve the integrity of ligamentous detachments should be selected, as the density of the receptors is much greater in this area.

In our study, we performed measurements on patients chosen for anatomical reconstruction. Summarising all directions, the afflicted side showed a significant improvement in mean absolute estimate errors compared with its preoperative joint position sense function. The main aim of surgery is the retensioning of the anterolateral structures. Because of the previously described mechanoreceptors, actual changes may only occur in supination and plantarflexion. As we excluded all potentially disturbing circumstances, differences between the two measurements must be interpreted as an effect of the surgical intervention. More detailed analysis shows that significant changes only occurred in two directions-anterior and lateral-both combined and separately. In the two other, theoretically unimportant, planes there were no major changes. The postoperative results for the affected side matched averages of both the healthy contralateral ankles and the control group. The study thus confirms that the preoperative differences in joint position sense function between the healthy and injured ankles had disappeared as the result of surgery.

Our results lead to two further important conclusions. Before surgery, the mean absolute estimate errors for the afflicted ankle were significantly larger than for the healthy ankle, and this difference was observed on lateral and anterior slopes. This shows that proprioceptive malfunction has a role in the development of chronic ankle instability. Disturbed joint position sense function is thus a causative factor of functional instability.

If treatment is by means of surgery, reconstruction and retensioning of the anterolateral structures is inevitable. This means that, even if any other kind of surgery is performed or

\section{What this study adds}

- Differences in joint position sense between healthy and injured ankles disappeared as the result of surgery

- Data obtained before surgery show that proprioceptive malfunction is a cause of functional instability 
any other kind of grafting is applied for mechanical stabilisation, anatomical reconstruction of the capsule and the ligaments must be carried out simultaneously. In the case of tendoplasties and periosteal-flap plasties, this technical addition is very simple, and will improve functional results, especially from the athlete's point of view.

\section{Authors' affiliations}

T Halasi, Á Kynsburg, A Tállay, I Berkes, Department of Sports Surgery, National Institute for Sports Medicine, Budapest, Hungary

Competing interests: none declared

\section{REFERENCES}

1 Hertel J. Functional instability following lateral ankle sprain. Sports Med 2000;29:361-71.

2 Karlsson J, Bergsten $T$, Lansinger $O$, et al. Reconstruction of the lateral ligaments of the ankle for chronic lateral instability. J Bone Joint Surg [Am] 1988;70:581-8.

3 Mann G, Eliashuv $\mathrm{O}$, Perry $\mathrm{C}$, et al. Recurrent ankle sprain: literature review. Israel Journal of Sports Medicine 1994:104-13.

4 Peters JW, Trevino SG, Renström PA. Chronic lateral ankle instability. Foot Ankle 1991;12:182-91.

5 Glencross D, Thornton E. Position sense following joint injury. J Sports Med 1981;21:23-7.

6 Konradsen L, Beynnon BD, Renström PA. Proprioception and sensorimotor control in the functionally unstable ankle. In: Lephart SM, Fu FH, eds. Proprioception and neuromuscular control in joint stability. Champaign, IL: Human Kinetics, 2000:237-47.

7 Karlsson J, Rudholm O, Bergsten T, et al. Early range of motion training after ligament reconstruction of the ankle joint. Knee Surg Sports Traumatol Arthrosc 1995;3:173-7.

8 Karlsson J, Eriksson BI, Bergsten T, et al. Comparison of two anatomic reconstructions for chronic lateral instability of the ankle joint. Am J Sports Med 1997; 25:48-53.

9 Williams JGP. Plication of the anterolateral capsule of the ankle with extensor digitorum brevis transfer for chronic lateral ligament instability. Injury 1988;19:65-9.

10 Ahlgren $\mathrm{O}$, Larsson S. Reconstruction for lateral ligament injuries of the ankle. $J$ Bone Joint Surg [Br] 1989;71:300-3.

11 Liu SH, Baker CL. Comparison of lateral ankle ligamentous reconstruction procedures. Am J Sports Med 1994;22:313-17.
12 Liu SH, Jacobson KE. A new operation for chronic lateral ankle instability. $J$ Bone Joint Surg [Br] 1995;77:55-9.

13 Gould N, Seligson D, Gassman J. Early and late repair of lateral ligament of the ankle. Foot Ankle 1980;1:84-9.

14 Broström L. Sprained ankles. VI. Surgical treatment of "chronic" ligament ruptures. Acta Chir Scand 1966;132:551-65.

15 Konradsen L, Beynnon BD, Renström PA. Techniques for measuring sensorimotor control of the ankle: evaluation of different methods. In: Lephart SM, Fu FH, eds. Proprioception and neuromuscular control in joint stability. Champaign, IL: Human Kinetics, 2000:139-45.

16 Robbins S, Waked E, Rappel R. Ankle taping improves proprioception before and after exercise in young men. Br J Sports Med 1995;29:242-7.

17 Lephart SM, Princivero DM, Giraldo JL, et al. The role of proprioception in the management and rehabilitation of athletic injuries. Am J Sports Med 1997;25:130-7.

18 Ashton-Miller JA. Proprioceptive thresholds at the ankle: implications for the prevention of ligamentous injury. In: Lephart SM, Fu FH, eds. Proprioception and neuromuscular control in joint stability. Champaign, IL: Human Kinetics, 2000:279-89.

19 Ashton-Miller JA, Wojtys EM, Huston $\amalg$, et al. Can proprioception really be improved by exercises? Knee Surg Sports Traumatol Arthrosc 2001;9:128-36.

20 Konradsen L, Ravn JB, Sørensen Al. Proprioception at the ankle: the effect of anaesthetic blockade of ligament receptors. J Bone Joint Surg $[\mathrm{Br}]$ 1993;75:433-6.

21 Renström PA, Konradsen L, Beynnon BD. Influence of knee and ankle support on proprioception and neuromuscular control. In: Lephart SM, Fu FH, eds. Proprioception and neuromuscular control in joint stability. Champaign, IL: Human Kinetics, 2000:301-9.

22 Konradsen L, Magnusson P. Increased inversion angle replication error in functional ankle instability. Knee Surg Sports Traumatol Arthrosc 2000;8:246-51.

23 Gross MT. Effect of recurrent lateral ankle sprains on active and passive judgments of joint position. Phys Ther 1987:67:1505-9.

24 Feuerbach JW, Grabiner MD, Koh TJ, et al. Effect of an ankle orthosis and ankle ligament anesthesia on ankle joint proprioception. Am J Sports Med 1994;22:223-9.

25 Hertel J, Guskiewicz KM, Kahler DM, et al. Effect of lateral ankle joint anaesthesia on center of balance, postural sway and joint position sense. J Sport Rehabil 1996;5:111-19.

26 Karlsson J, Bergsten T, Lansinger $O$, et al. Surgical treatment of chronic lateral instability of the ankle joint, a new procedure. Am J Sports Med 1989:17:268-73.

27 Takebayashi T, Yamashita T, Minaki Y, et al. Mechanosensitive afferent units in the lateral ligament of the ankle. J Bone Joint Surg $[\mathrm{Br}]$ 1997;79:490-3. 